\title{
Co-Precipitation of Beta-Carotene and Bio-Polymer Using Supercritical Carbon Dioxide as Antisolvent
}

\author{
Elton Franceschi*, ${ }^{*}$, Alana de Cezaro ${ }^{2}$, Sandra R. S. Ferreira ${ }^{3}$, Marcos H. Kunita ${ }^{4}$, Edvani C. \\ Muniz $^{4}$, Adley F. Rubira ${ }^{4}$ and J. Vladimir Oliveira ${ }^{2}$
}

\begin{abstract}
${ }^{1}$ Instituto de Tecnologia e Pesquisa-ITP, Programa de Mestrado em Engenharia de Processos PEP/UNIT, Campus Farolândia, Av. Murilo Dantas, 300, Aracaju, SE, 49032-490, Brazil

${ }^{2}$ Department of Food Engineering, URI - Campus de Erechim, Av. Sete de Setembro, 1621, Erechim, RS 99700-000, Brazil

${ }^{3}$ EQA-CTC/UFSC, Chemical Engineering and Food Engineering Department, Federal University of Santa Catarina, C.P. 476, CEP 88040-900, Florianópolis, SC, Brazil
\end{abstract}

${ }^{4}$ Department of Chemistry, Universidade Estadual de Maringá, Av. Colombo 5790, 87020-900, Maringá, PR, Brazil

\begin{abstract}
The objective of this work was to investigate the application of supercritical carbon dioxide as antisolvent for the co-precipitation of $\beta$-carotene and poly(hydroxybutirate-co-hydroxyvalerate) (PHBV) with dichloromethane as organic solvent. For this purpose, the concentrations of $\beta$-carotene $\left(1\right.$ to $\left.8 \mathrm{mg} . \mathrm{cm}^{-3}\right)$ and PHBV $\left(20\right.$ to $\left.40 \mathrm{mg} . \mathrm{cm}^{-3}\right)$ in the organic solution were varied keeping fixed temperature at $313 \mathrm{~K}$, pressure at $8 \mathrm{MPa}$, solution flow rate at $1 \mathrm{~cm}^{3} \cdot \mathrm{min}^{-1}$ and antisolvent flow rate at $39 \mathrm{~g} \cdot \mathrm{min}^{-1}$. The morphology of co-precipitated particles were spherical with very irregular and porous surface for some conditions and very smooth surfaces for others as verified by micrographs of scanning electronic microscopy (SEM). Results show that it is possible to achieve encapsulation efficiency values as high as $35 \%$ just manipulating the concentration ratio of solute to polymer in organic solution. The methodology adopted for the quantification of $\beta$-carotene encapsulated was demonstrated to be adequate.
\end{abstract}

Keywords: Encapsulation, beta-carotene, carbon dioxide, bio-polymer, SEDS technique.

\section{INTRODUCTION}

Carotenoids are constituted by a great group of pigments present in nature. There are more than 600 different types of carotenoids but only 40 of them are present in foods. The most abundant are $\beta$-carotene, lycopene, lutein and zeaxanthin. The main role of these compounds in human health is as vitamin A precursors, antioxidants that can lead to a decrease in risk of diseases as cancer [1-3]. They also are widely used in the food, cosmetic and pharmaceutical industries [1]. In the food industry, they are applied as colorants for color recovering lost during processing and storage and, as well as color standardization of some products.

Due to their above mentioned functional activities, carotenoids can also be added in food products in order to increase the functionality of foods. Many important chemical compounds responsible for food aroma, specific color and photoprotection are derived from carotenoids [4]. The presence of small amounts of carotenoids in the foods still can help to prevent from the fast oxidation of lipids present in foods, quenching singlet oxygen [5].

Due to high unsaturated chain, extended exposition to light, heat and acids may cause isomerization of trans-

*Address correspondence to this author at the Instituto de Tecnologia e Pesquisa-ITP, Programa de Mestrado em Engenharia de Processos PEP/UNIT, Campus Farolândia, Av. Murilo Dantas, 300, Aracaju, SE, 49032-490, Brazil; Fax: +55-79-32182190; E-mail: elton@itp.org.br carotenoids, the (stable form), to cis form, promoting slight loss of color and pro-vitamin activity. They also are susceptible to enzymatic and non enzymatic oxidation and this reaction depend on the carotenoid structure, oxygen availability, and presence of enzymes, metals, prooxidants and antioxidants [5].

Different from synthetic carotenoids, the ones obtained from natural sources (microorganisms and nature) are easily oxidized [6] and their oxidation products afford small or negligible pigmentation, pro-vitamin and quenching of singlet oxygen activity [7].

Formulations of polymer and active compounds in the micrometric range are gaining increasing interest by food industries for the development of high quality products, shelf-life increase of perishable foods and incorporation of vitamins and nutraceutical compounds in some foods. Such formulations are made, generally, by some active compound impregnated or encapsulated in a biopolymer. These compounds can act as anti-microbial agent, enhancing the color and taste or even as supplement in human health. Conventional techniques employed to obtain such formulations becomes onerous in providing inputs with high purity and adequate characteristics for food use. Rigid regulations in the use of organic solvents and their residual values in the final products are the main restriction of these techniques [8].

Regarding the encapsulation of active compounds, there are basically two methods: the compound can be covered by 
a polymer thin layer or the compound and polymer can be co-precipitated generating fine particles of the active compound impregnated into polymeric particles. The encapsulation, also called micro or nano-capsules, occur when the active compound to be encapsulated is suspended into a polymeric solution and then the polymer is precipitated recovering the active compound particles. The co-precipitation occurs when the compound to be encapsulated and the polymer are dissolved in an organic solvent or solvent mixture and simultaneously precipitated [9, 10]. In the last method, according to literature, the more important variable that affects the morphology, the encapsulation efficiency and yield is the ratio between the concentration of polymer and active compound into organic solution $[11,12]$.

There is a range of polymers that can be employed to encapsulate bioactive compounds, due to their biocompatibility and biodegradability. Several biopolymers were already used to encapsulate pharmaceutical compounds [9, 13], proteins [14-16], and carotenoids [3, 17]. The polymer used for encapsulation plays a crucial role, because the polymer characteristics determine the release of the encapsulated solute. The delivery can occur in two ways: diffusion or degradation release. The first mechanism takes place when the incorporated compound passes through the polymer pores or through the polymer chain. Degradation release occurs when a polymer degrades within the food matrix, as a result of natural biological process such as hydrolysis. In this case, the polymer degradation is strongly dependent on the chemical structure and molecular mass of the polymer [13].

Polyhydroxyalkanoates (PHA) are polyesters produced by microorganisms under unbalanced growth conditions. PHA is generally biodegradable, with good biocompatibility, hence an attractive polymer for use as encapsulating agent [18]. The most common type of PHA is poly (3hydroxibutirate) (PHB). However, PHB is stiff and brittle thus restricting its range of application. On the other hand, PHB copolymers with 3-hydroxyvalerate (PHBV) are less stiff, tougher and crystalline [19]. The use of PHBV in biomedical field has increased mainly due to the fact that it is possible to prepare an appropriate controlled drug delivery system that gradually degrades in the body [18]. Thus, the copolymer PHBV can also be used as encapsulation medium for the protection and controlled delivery of carotenoids in foods.

The particle formation and encapsulation using traditional techniques (spray-drying, coacervation, freeze-drying, interfacial polymerization, etc.) can suffer from some drawbacks like poor control of particle size and morphology, degradation of thermo sensitive compounds, low encapsulation efficiency, and/or low yield.

In this sense, several supercritical fluid-based techniques, employing mainly carbon dioxide, have been proposed to explore the solvent strength, the high diffusivity and the near-zero interfacial tension that are peculiar in the vicinity of the critical point [20]. The use of supercritical or near critical fluids as solvents or antisolvents for particle precipitation/encapsulation was considered useful tools to modify of material properties such as particle size, size distribution and morphology. Another advantage of such techniques is the efficient separation of the solvent and antisolvent of the particles after precipitation, preventing organic solvent resi- dues in the final product and permitting reutilization of solvent and antisolvent [21].

In this context, the objective of this work was to investigate the effect of $\beta$-carotene and PHBV concentrations in organic solution on the encapsulation efficiency and encapsulation yield of $\beta$-carotene into PHBV by the coprecipitation of them using the SEDS technique employing supercritical carbon dioxide as anti solvent and dichloromethane as organic solvent. All other variables (temperature, pressure, solution and antisolvent flow rate) were kept constant based on previous works of the group [22-24]. The morphology of precipitated powders was characterized by scanning electronic microscopy (SEM) and the percentage of encapsulation and encapsulation efficiency was verified by UV-vis spectrophotometry.

\section{EXPERIMENTAL}

\section{Materials}

Trans- $\beta$-carotene, with a purity of $95 \%$, was purchased from Sigma-Aldrich (USA). Dichloromethane (DCM - 99.5 $\%)$ was purchased from Merck (Germany), carbon dioxide (99.9\% purity) was supplied by White Martins S.A., and the co-polymer Poly(3-hydroxybutirate-co-hydroxyvalerate) (PHBV), with molar mass $\left(\mathrm{M}_{\mathrm{w}}\right)$ of 196000 and polydispersity index of 1.85 , was kindly supplied by the PHB Industrial S.A. All materials were used as received.

\section{Co-precipitation Apparatus and Procedure}

Fig. (1) presents a schematic diagram of the experimental apparatus employed for co-precipitation of $\beta$-carotene and PHBV using the SEDS technique. Briefly, it consists of a cylindrical vessel, with an internal volume of $600 \mathrm{~cm}^{3}$ and internal diameter of $8 \mathrm{~cm}$, which was used as precipitation chamber (PC); two syringe pumps for $\mathrm{CO}_{2}$ displacement (ISCO, Model 500D), operated independently by a set of ball valves - V1 to V4 (Swagelok, Model SS-83KS4), and a digital HPLC liquid pump (Acuflow, Series III) used for organic solution delivery.

The organic solution was sprayed into the precipitation chamber at a flow rate of $1 \mathrm{~cm}^{3} \cdot \mathrm{min}^{-1}$ through a silica capillary fusing tube, with an internal diameter of $100 \mu \mathrm{m}$, connected to a polyetheretherketone tubing (Peek Tubing, Upchurch Scientific). This arrangement was linked to a BPR (back pressure regulator, GO-Regulator, Series BP-66, Model 1A11QEQ151) and to a tee (T) connector (Swagelok), to link the antisolvent and the solution flows.

During the experiments, the temperature in the precipitation chamber was kept constant at $313 \mathrm{~K}$ by an ultrathermostactic bath (Nova Ética, Model 521/2D), while the pressure was controlled at $8.0 \mathrm{MPa}$ by two needle valves (HIP, Model 15-11AF1). The first valve (V5) controlled the antisolvent flow rate $\left(39\right.$ g. $\left.\mathrm{min}^{-1}\right)$, while the other one controlled the depressurization. A second vessel (SC) connected after valve V6 was used to keep the stream that leaves the precipitation chamber at a relatively low pressure (about $4 \mathrm{MPa}$ ) to prevent the blockage of such valve. A system used for powder collection was located in the bottom of the precipitation chamber, and was composed by sintherized metal filter (superficial porosity of $1.0 \mu \mathrm{m}$ ) as a support to the polytetrafluorethylene membrane filter linked to a high density poly- 


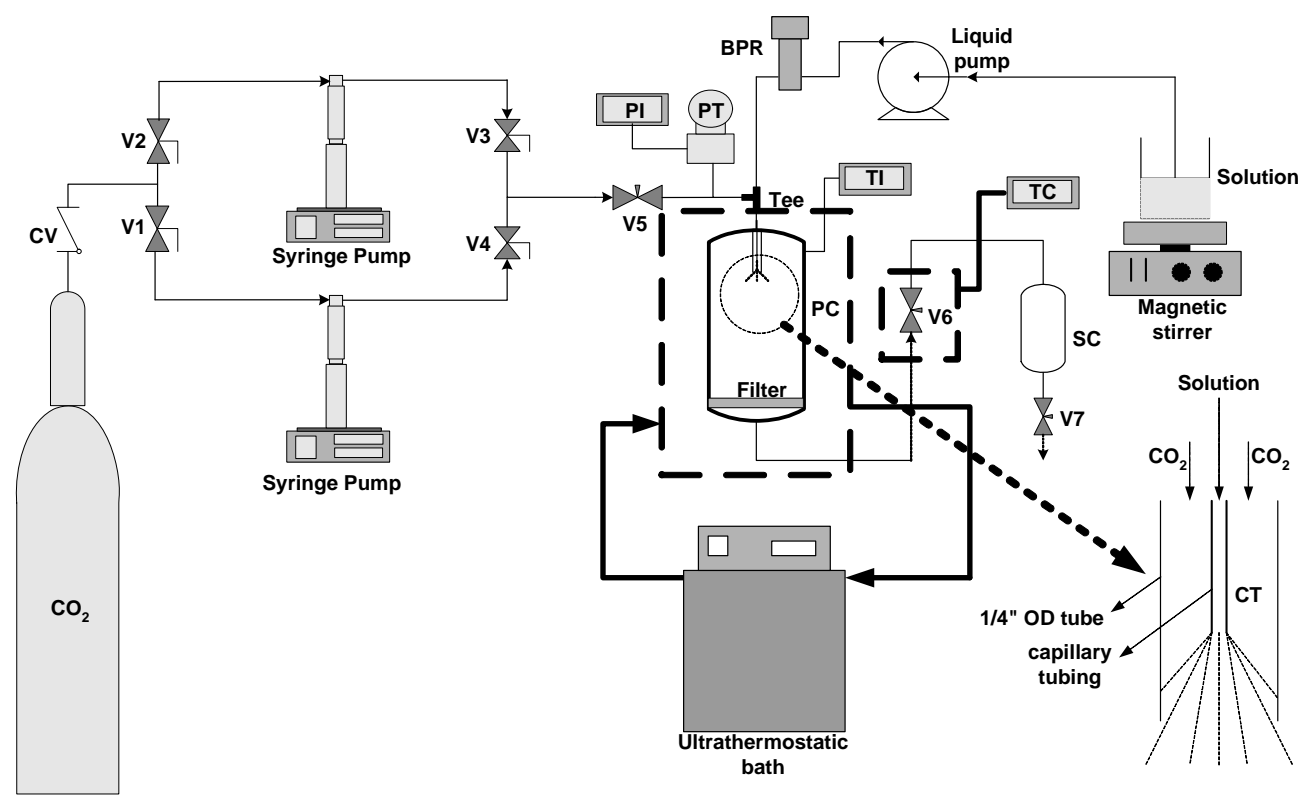

Fig. (1). Schematic diagram of the co-precipitation apparatus. CV - check-valve; V1, V2, V3 and V4 - ball valve; V5, V6 and V7 - needle valve; BPR - back pressure regulator; PT - pressure transducer; PI - Pressure indicator; TI - temperature indicator; TC - temperature control; PC - precipitation chamber; SC - separation chamber; CT - capillary tube.

Table 1. Experimental Conditions of $\beta$-Carotene and PHBV Co-Precipitation Using Dichloromethane as Organic Solvent and Carbon Dioxide as Antisolvent by the SEDS Technique; Temperature of 313 K, Pressure of 8.0 MPa, Solution Flow Rate of 1 $\mathrm{cm}^{3} \cdot \mathrm{min}^{-1}$ and, Antisolvent Flow Rate of $39 \mathrm{~g} \cdot \mathrm{min}$

\begin{tabular}{|c|c|c|c|}
\hline Run & $\begin{array}{c}\beta \text {-Carotene Concentration Into Organic } \\
\text { Solution }\left({\left.\mathrm{mg} . \mathrm{cm}^{-3}\right)}^{-3}\right.\end{array}$ & $\begin{array}{l}\text { PHBV Concentration Into Organic Solu- } \\
\text { tion }\left(\mathrm{mg}^{\left.-\mathrm{cm}^{-3}\right)}\right.\end{array}$ & $\begin{array}{c}\text { Percentage of } \beta \text {-Carotene } \\
(w t \%)\end{array}$ \\
\hline 1 & 8.04 & 20.01 & 28.7 \\
\hline 2 & 6.01 & 19.99 & 23.1 \\
\hline 3 & 4.01 & 19.90 & 16.8 \\
\hline 4 & 2.02 & 20.04 & 9.2 \\
\hline 5 & 1.00 & 20.01 & 4.8 \\
\hline 6 & 8.07 & 30.08 & 21.2 \\
\hline 7 & 6.04 & 30.02 & 16.8 \\
\hline 8 & 4.04 & 30.07 & 11.8 \\
\hline 9 & 1.99 & 30.02 & 6.2 \\
\hline 10 & 0.99 & 30.00 & 3.2 \\
\hline 11 & 7.99 & 40.01 & 16.7 \\
\hline 12 & 6.03 & 40.03 & 13.1 \\
\hline 13 & 4.01 & 40.01 & 9.1 \\
\hline 14 & 2.01 & 40.09 & 4.8 \\
\hline 15 & 1.03 & 40.06 & 2.5 \\
\hline
\end{tabular}

ethylene support (Millipore, model FGLP with a porosity of $0.22 \mu \mathrm{m})$.

The experimental procedure started with $\mathrm{CO}_{2}$ filling the precipitation chamber up to the desired pressure. The antisolvent flow rate was controlled by setting V5 and V6 valves, and monitored by the syringe pump. When the temperature, pressure and antisolvent flow rate were stabilized, the organic solution was added through the capillary tubing. The pressure for solution spray into the precipitator was controlled by BPR manipulation and monitored by the liquid pump. The solution volume added to the chamber was 20 
$\mathrm{cm}^{3}$, enabling the collection of sufficient amount of precipitated powder for analysis. After the solution was added, near $800 \mathrm{~cm}^{3}$ of $\mathrm{CO}_{2}$ was continuously flowed inside the precipitation chamber in order to dry the precipitated particles. The precipitation chamber was then slowly depressurized to atmospheric pressure and particles were collected and stored at appropriate conditions for subsequent analysis and characterization. A more detailed description of the apparatus and experimental procedure can be found elsewhere [22, 23].

\section{Co-Precipitation Conditions}

The literature reports that the most important variable affecting the percentage of encapsulation (PE\%) and encapsulation efficiency $(\mathrm{EE} \%)$ is the concentration ratio between the compound to be encapsulated and the polymer in the organic solution. Therefore, in this work the parameter values adopted for co-precipitation of $\beta$-carotene and PHBV, based on previous results [24] that afforded the smaler particle size of $\beta$-carotene $(3.2 \mu \mathrm{m})$, were: temperature of $313 \mathrm{~K}$, pressure of $8.0 \mathrm{MPa}$, solution flow rate of $1 \mathrm{~cm}^{3} \cdot \mathrm{min}^{-1}$ and antisolvent flow rate of $39 \mathrm{~g} \cdot \mathrm{min}^{-1}$. These parameter values were maintained constant for all experimental conditions.

The effect of $\beta$-carotene and PHBV concentration into organic solution was investigated between 1 to $8 \mathrm{mg} . \mathrm{cm}^{-3}$ and 20 to $40 \mathrm{mg} . \mathrm{cm}^{-3}$, respectively. Concentration values of $\beta$-carotene were based on the work of Tres et al [25], while polymer concentrations were based on results obtained by our group, not published yet. The concentrations of $\beta$ carotene and PHBV varied in the organic solution gave the objective of study the influence of different concentrations of $\beta$-carotene and PHBV into organic solution on the percentage of encapsulation (PE\%) and encapsulation efficiency (EE\%). The experimental conditions investigated in this work are summarized in Table 1.

\section{Analysis and Characterization}

Co-precipitated particles were analyzed by a Shimadzu model SS-550 Superscan scanning electron microscope (SEM) to determine particle morphology and shape. Particle size and particle size distribution of the co-precipitated were measured by the Size Meter software (version 1.1), using at least 500 particles for each experiment.

To determine the percentage of encapsulation, the literature reports different techniques, like the high performance liquid chromatography $[9,13,26]$ and UV spectrophotometry [17, 27-29]. In this work the percentage of encapsulation was verified by an UV-Vis spectrophotometer.

The amount of $\beta$-carotene encapsulated was determined by the following procedure: initially, a sample of coprecipitated $\beta$-carotene and PHBV was weighted (between 5 to $35 \mathrm{mg}$ ) in an analytical balance with precision of 0.00001g (Mettler Toledo, model XS205 Dual Range) and was added to different volumes of acetone to remove nonencapsulated $\beta$-carotene. The suspensions of co-precipitated into acetone were ultrasonicated at different times; the selected times were $0,0.5,1,2$ and 3 minutes based on literature data that employed different agitation times and reported different percentage of encapsulation [9, 13, 17, 27-29]. After ultrasonication all samples were filtered using a membrane filter with porosity of $0.22 \mu \mathrm{m}$ (Millipore, model
FGLP). The zero time was a condition not submitted to ultrasonication and in this case a mass of co-precipitated was suspended in acetone and filtered. After filtration, retained sample was dried at controlled temperature $(323 \mathrm{~K})$ and vacuum for $24 \mathrm{~h}$. Afterwards, the dried powder was dissolved in dichloromethane and the solution was analyzed in a spectrophotometer (Agilent UV-visible, model 8453DE). The absorbance of $\beta$-carotene was measured at $460 \mathrm{~nm}$. Comparing the results with a pattern curve of absorbance vs. concentration of $\beta$-carotene in the solvent, the percentage of $\beta$ carotene encapsulated (PE\%) and the efficiency of encapsulation $(\mathrm{EE} \%)$ in each experimental run were evaluated by the following expressions [9]:

$$
\begin{aligned}
& \mathrm{PE}[\%]=\frac{\text { mass of } \beta \text {-carotene encapsulated }}{(\text { mass of } \beta \text {-carotene }+ \text { mass of PHBV }) \text { after filtration }} \times 100 \\
& \mathrm{EE}[\%]=\frac{\text { percentage of } \beta \text {-carotene encapsulated }}{\text { theoretical percentage of } \beta \text {-carotene encapsulated }} \times 100
\end{aligned}
$$

where the theoretical percentage of $\beta$-carotene encapsulated is the ratio between the mass of $\beta$-carotene and the total mass of $\beta$-carotene and PHBV used in the co-precipitation experiments, which means that the maximum $\beta$-carotene encapsulated will correspond to the theoretical percentage of encapsulation.

Starting from the values of the percentage of encapsulation calculated from Equation 1, an experimental curve of percentage of encapsulation vs. time of ultrasonication was constructed for each experimental run. An empirical model was then built by regression of experimental data employing the software Statistica $6.0^{\circledR}$ through the SIMPLEX method. With the empirical model it was possible to determine the percentage of encapsulation. The general expression of the empirical model fitted was:

$$
P E \%=A_{1} \times \exp \left(A_{2} \times \text { time }\right)+A_{3}
$$

where $\mathrm{PE} \%$ denotes the percentage of encapsulation given by the empirical model, $A_{1}, A_{2}$ and $A_{3}$ are adjustable parameters and time is in minutes.

\section{RESULTS AND DISCUSSIONS}

The main idea for co-precipitation is that the particles of the core material precipitated are smaller than those of the encapsulating material. In this sense, it was chosen the best result obtained in our previous work on precipitation of pure $\beta$-carotene using the SEDS technique [24]. In that work, the variable values that gave the smaller particle size of $\beta$ carotene $(3.2 \mu \mathrm{m})$ was: temperature of $313 \mathrm{~K}$, pressure of 8.0 $\mathrm{MPa}$, solution flow rate of $1 \mathrm{~cm}^{3} \cdot \mathrm{min}^{-1}$ and antisolvent flow rate of 39 g. $\mathrm{min}^{-1}$. In this work, the same variables and their values were used and the co-precipitation of $\beta$-carotene and PHBV was carried out using dichloromethane as organic solvent and supercritical carbon dioxide as antisolvent employing the SEDS technique. As the literature points out that the more important variable that affect the percentage of encapsulation and the encapsulation efficiency is the ratio between solute and biopolymer in organic solution, the effect of $\beta$-carotene and PHBV concentration into organic solution was investigated from 1 to $8 \mathrm{mg} \cdot \mathrm{cm}^{-3}$ and 20 to $40 \mathrm{mg} \cdot \mathrm{cm}^{-3}$, respectively. For the determination of $\beta$-carotene encapsulated, samples were submitted to ultrasonication and Equation 1 was employed. Results in terms of percentage of $\beta$ - 
Table 2. Percentage of Encapsulated $\beta$-Carotene in PHBV Using Dichloromethane as Organic Solvent and $\mathrm{CO}_{2}$ as Antisolvent According to Different Ultrasonication Times to Remove The Non-Encapsulated $\beta$-Carotene

\begin{tabular}{|c|c|c|c|c|c|}
\hline \multirow{2}{*}{ Run } & \multicolumn{5}{|c|}{ Percentage of $\beta$-Carotene Encapsulated with Different Ultrasonication Times } \\
\hline & $0 \mathrm{~min}$ & $0.5 \mathrm{~min}$ & $1 \mathrm{~min}$ & $2 \mathrm{~min}$ & $3 \mathrm{~min}$ \\
\hline 1 & $22.7 \pm 0.2$ & $5.5 \pm 0.1$ & $0.22 \pm 0.01$ & $0.18 \pm 0.01$ & $0.22 \pm 0.01$ \\
\hline 2 & $20.5 \pm 0.1$ & $3.1 \pm 0.1$ & $0.15 \pm 0.03$ & $0.11 \pm 0.01$ & $0.09 \pm 0.01$ \\
\hline 3 & $14.2 \pm 0.1$ & $0.6 \pm 0.1$ & $0.25 \pm 0.01$ & $0.18 \pm 0.01$ & $0.13 \pm 0.01$ \\
\hline 4 & $6.1 \pm 0.1$ & $1.9 \pm 0.1$ & $0.28 \pm 0.02$ & $0.16 \pm 0.01$ & $0.05 \pm 0.01$ \\
\hline 5 & $3.6 \pm 0.1$ & $0.3 \pm 0.1$ & $0.20 \pm 0.01$ & $0.15 \pm 0.02$ & $0.09 \pm 0.01$ \\
\hline 6 & $19.2 \pm 0.1$ & $4.3 \pm 0.3$ & $2.10 \pm 0.03$ & $0.50 \pm 0.01$ & $0.30 \pm 0.01$ \\
\hline 7 & $11.7 \pm 0.2$ & $2.6 \pm 0.1$ & $0.22 \pm 0.01$ & $0.02 \pm 0.01$ & $0.05 \pm 0.01$ \\
\hline 8 & $11.4 \pm 0.1$ & $1.2 \pm 0.1$ & $0.19 \pm 0.01$ & $0.33 \pm 0.01$ & $0.24 \pm 0.01$ \\
\hline 9 & $4.7 \pm 0.1$ & $0.5 \pm 0.1$ & $0.12 \pm 0.01$ & $0.12 \pm 0.01$ & $0.08 \pm 0.01$ \\
\hline 10 & $2.3 \pm 0.1$ & $0.4 \pm 0.1$ & $0.20 \pm 0.01$ & $0.11 \pm 0.01$ & $0.09 \pm 0.01$ \\
\hline 11 & $12.0 \pm 0.2$ & $11.1 \pm 0.3$ & $4.95 \pm 0.01$ & $3.63 \pm 0.04$ & $1.86 \pm 0.07$ \\
\hline 12 & $8.9 \pm 0.1$ & $1.7 \pm 0.1$ & $0.21 \pm 0.01$ & $0.17 \pm 0.01$ & $0.07 \pm 0.01$ \\
\hline 13 & $5.4 \pm 0.1$ & $2.2 \pm 0.1$ & $0.15 \pm 0.01$ & $0.32 \pm 0.01$ & $0.15 \pm 0.01$ \\
\hline 14 & $3.5 \pm 0.1$ & $1.3 \pm 0.1$ & $0.55 \pm 0.01$ & $0.46 \pm 0.01$ & $0.26 \pm 0.01$ \\
\hline 15 & $1.2 \pm 0.1$ & $0.4 \pm 0.1$ & $0.09 \pm 0.01$ & $0.04 \pm 0.01$ & $0.03 \pm 0.01$ \\
\hline
\end{tabular}

carotene encapsulation (PE\%) and encapsulation efficiency $(\mathrm{EE} \%)$ are presented in Table 2.

Table 2 shows that as ultrasonication time increases the percentage of encapsulation decreases. A notable decrease is observed comparing the percentage of encapsulation of the samples that are only suspended in acetone and filtered with the samples that were ultrasonicated for 0.5 minutes. It can be also observed that the percentage of encapsulation increases with the increase in $\beta$-carotene concentration into the solution.

When the mass percentage of $\beta$-carotene is kept constant regarding the total mass of $\beta$-carotene plus PHBV, the conditions where the solution was more concentrated in $\beta$ carotene gave the highest percentage of encapsulation. For example, comparing the co-precipitation condition at $\beta$ carotene and PHBV concentrations of $2 \mathrm{mg} . \mathrm{cm}^{-3}$ and 20 $\mathrm{mg} . \mathrm{cm}^{-3}$ respectively, into organic solution with the condition at $\beta$-carotene and PHBV concentrations of $4 \mathrm{mg} . \mathrm{cm}^{-3}$ and $40 \mathrm{mg} . \mathrm{cm}^{-3}$, respectively into organic solution, it can be observed that in the more concentrated solution the percentage of encapsulation for the different ultrasonication times is higher than of the more concentrated solution.

In the more diluted solution, with $\beta$-carotene concentration of $2 \mathrm{mg} \cdot \mathrm{cm}^{-3}$ (experimental condition 4), as the concentration of $\beta$-carotene is smaller than the experimental condition with $\beta$-carotene concentration of $4 \mathrm{mg} . \mathrm{cm}^{-3}$ (experimental condition 13), the precipitation kinetic is slower, having more polymer particles to be precipitated than $\beta$-carotene particles, leading to the precipitation of $\beta$-carotene onto polymer surface of precipitated particles. In the experimental condition 13, the concentration of $\beta$-carotene in organic solution is higher than that of the experimental condition 4 , leading to a faster precipitation kinetic of $\beta$-carotene. Thus, $\beta$ carotene and polymer precipitate simultaneously, causing the encapsulation of $\beta$-carotene into polymer particles.

Other assumption that might explain this phenomenon is the porosity of the polymer particles generated during the coprecipitation. More porous polymer particles allow the solvent employed to remove the non-encapsulated $\beta$-carotene to enter into the pore of the polymer particles and dissolve even the encapsulated $\beta$-carotene. Fig. (2) shows SEM micrographs of the experimental co-precipitation conditions with $\beta$-carotene and PHBV concentration of $2 \mathrm{mg} \cdot \mathrm{cm}^{-3}$ and 20 mg.cm ${ }^{-3}$, respectively (Fig. 2A) and at $\beta$-carotene and PHBV concentration of $4 \mathrm{mg} . \mathrm{cm}^{-3}$ and $40 \mathrm{mg} . \mathrm{cm}^{-3}$, respectively (Fig. 2B).

As can be seen from this figure, for the more diluted solution (Fig. 2A) the polymer particle size was around $15 \mu \mathrm{m}$ and for the more concentrated solution (Fig. 2B) the polymer particle size was about $50 \mu \mathrm{m}$. Increasing the polymer concentration into organic solution leads to an increase in particle size. Polymer particles of larger sizes are more susceptible to encapsulate the fine $\beta$-carotene particles. In Fig. (2A) it can be seen several particles of $\beta$-carotene attached on the surface of polymer particles, demonstrating that the precipitation kinetic of $\beta$-carotene in the more diluted solution is slower than that in more concentrated solution, that in turns does not present $\beta$-carotene particles attached on the surface of polymer particles. 


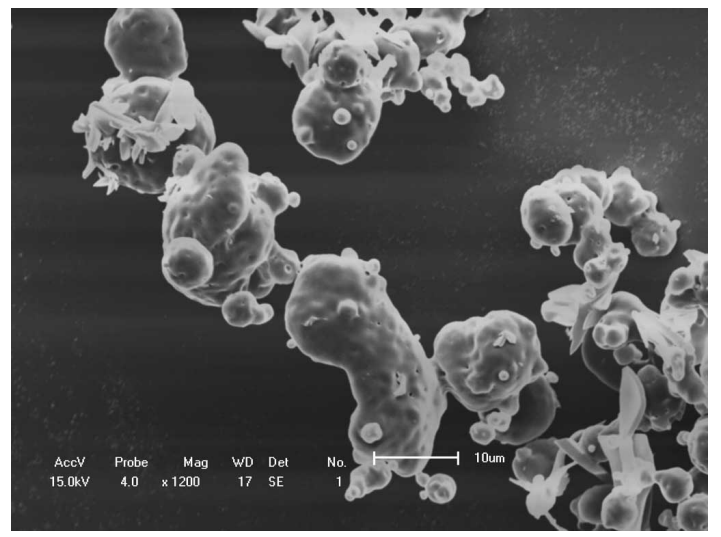

(A)

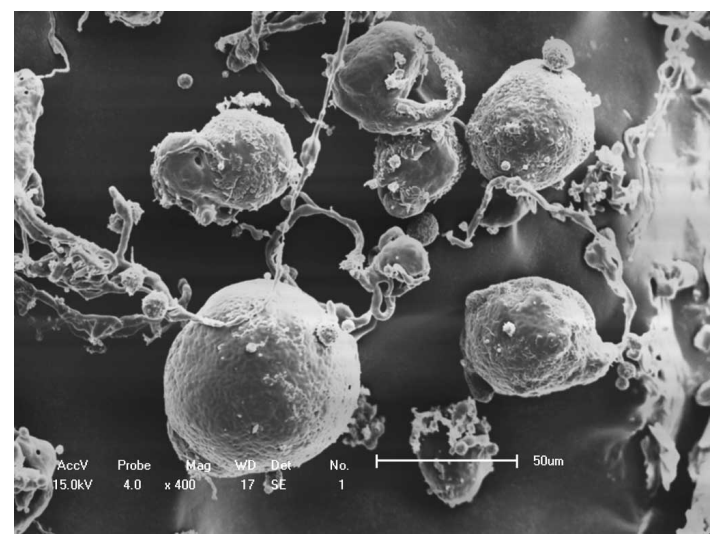

(B)

Fig. (2). SEM micrographs of the co-precipitation experimental condition with $\beta$-carotene and PHBV concentrations of $2 \mathrm{mg} . \mathrm{cm}^{-3}$ and 20 $\mathrm{mg} . \mathrm{cm}^{-3}$, respectively, into organic solution (A) with magnification of 1200 times, and experimental condition with $\beta$-carotene and PHBV concentrations of $4 \mathrm{mg} . \mathrm{cm}^{-3}$ and $40 \mathrm{mg} \cdot \mathrm{cm}^{-3}$, respectively, into organic solution (B) with magnification of 400 times. Precipitation pressure of $8.0 \mathrm{MPa}$, precipitation temperature of $313 \mathrm{~K}$, solution flow rate of $1 \mathrm{~cm}^{3} \cdot \mathrm{min}^{-1}$ and, antisolvent flow rate of $39 \mathrm{~g} \cdot \mathrm{min}^{-1}$.

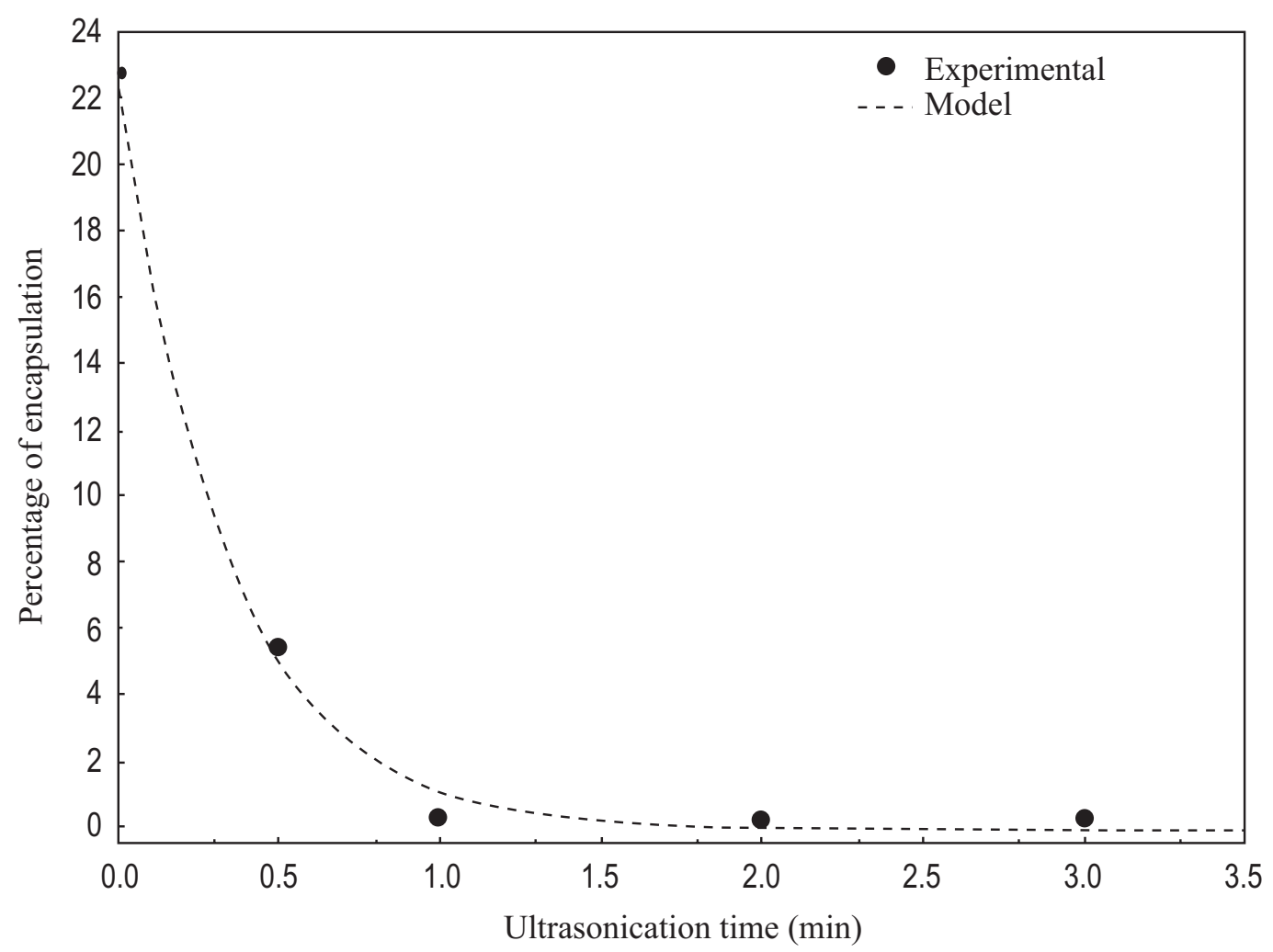

Fig. (3). Percentage of encapsulation as a function ultrasonication time for experimental condition with $\beta$-carotene and PHBV concentrations of $8 \mathrm{mg} . \mathrm{cm}^{-3}$ and $20 \mathrm{mg} \cdot \mathrm{cm}^{-3}$, respectively, into organic solution. Precipitation pressure of $8.0 \mathrm{MPa}$, precipitation temperature of $313 \mathrm{~K}$, solution flow rate of $1 \mathrm{~cm}^{3} \cdot \mathrm{min}^{-1}$ and, antisolvent flow rate of $39 \mathrm{~g} \cdot \mathrm{min}^{-1}$.

The percentage of encapsulation and encapsulation efficiency data are presented in Table $\mathbf{4}$ for all experimental conditions. The results of percentage of encapsulation were evaluated according to the time of ultrasonication, as presented in Fig. (3), which also shows the curve of the empirical model generated by data regression of experimental condition at $\beta$-carotene and PHBV concentrations of $8 \mathrm{mg} . \mathrm{cm}^{-3}$ and $20 \mathrm{mg} . \mathrm{cm}^{-3}$ respectively.
As can be observed from this figure, a sharp decrease in the percentage of encapsulation is noted for small ultrasonication times. The behavior observed for all other coprecipitation experiments was similar to that shown in Fig. (3), which is quite similar to the kinetic curves obtained from supercritical extraction of vegetable matrices, when the mass of extract is plotted against extraction time. Here, the percentage of encapsulation vs. ultrasonication time for the re- 
Table 3. Values of Adjustable Parameters and Time Needed to Remove the Non-Encapsulated $\beta$-Carotene

\begin{tabular}{|c|c|c|c|c|}
\hline Experimental Condition & $\mathbf{A}_{1}$ & $\mathbf{A}_{2}$ & $\mathbf{A}_{3}$ & $\begin{array}{l}\text { Time } \\
\text { (min) }\end{array}$ \\
\hline 1 & 22.826 & -2.968 & -0.093 & 0.3527 \\
\hline 3 & 14.028 & -7.057 & 0.181 & 0.1859 \\
\hline 4 & 6.117 & -2.518 & 0.020 & 0.4500 \\
\hline 6 & 9.006 & -1.551 & 0.166 & 0.6222 \\
\hline 7 & 11.789 & -3.093 & -0.058 & 0.3450 \\
\hline 8 & 11.083 & -4.995 & 0.356 & 0.2174 \\
\hline 9 & 4.487 & -5.565 & 0.174 & 0.2072 \\
\hline 13 & 5.330 & -2.073 & 0.127 & 0.5340 \\
\hline 14 & 3.164 & -2.432 & 0.329 & 0.5122 \\
\hline 15 & 1.214 & -2.389 & 0.019 & 0.5230 \\
\hline
\end{tabular}

moval of non-encapsulated $\beta$-carotene is an exponentialdecreasing time function.

In this sense, the methodology adopted here for the calculation of the percentage of encapsulation and encapsulation efficiency makes an analogy to the supercritical extraction technique. As described in the literature [30, 31] there are three extraction steps: the first one takes place at constant rate, where the external surface of the particles is covered with (free) solute to be extracted. Thus, this amount of solute will be easily extracted and the resistance to mass transfer is in the solvent phase. The second step is a decreasing extraction rate, in which the majority of solute present on the particle surface has been extracted, thus, the extraction is due to convection and diffusion across the particle pore. The third step is totally controlled by solute diffusion across the pores up to the particle surface. The three steps are present in the curve (Fig. 3). At the beginning, there is a linear and fast decrease of the percentage of encapsulation, meaning that only free $\beta$-carotene or weakly attached solute on the polymer particles is removed. If samples of the co-precipitated are left more time under ultrasonication, then begins the dissolution of $\beta$-carotene partially encapsulated and, for larger times start takes place the removal of encapsulated $\beta$ carotene by diffusion across the pores of the polymer particles. For the determination of the real percentage of encapsulation it was assumed that in the linear step only notencapsulated $\beta$-carotene was removed and a tangent was taken at the zero time of ultrasonication. The tangent was extended up to abscissa-axis, thus allowing the determination of the time needed to remove the non-encapsulated $\beta$ carotene. Table 3 presents the time needed to remove the non-encapsulated $\beta$-carotene and the adjustable parameters of Equation (3) for all experimental runs. With such information it is possible to determine the percentage of encapsulation for all experimental runs of co-precipitation.
The values of the percentage of encapsulation and encapsulation efficiency are presented in Table $\mathbf{4}$, that also presents the $\beta$-carotene and PHBV concentration into organic solution.

The percentage of encapsulation was in the range of 0.37 to $7.92 \%$ depending on the experimental co-precipitation condition (Table 4). The encapsulation efficiency varied between 16.7 and $34.7 \%$. The experimental condition that presented the smallest percentage of encapsulation was at $\beta$ carotene concentration of $1 \mathrm{mg} . \mathrm{cm}^{-3}$ and PHBV concentration of $40 \mathrm{mg} . \mathrm{cm}^{-3}$. In this condition, due to the high polymer concentration, the biopolymer precipitated as big spherical particles. For the solute, however, the $\beta$-carotene precipitation probably do not happen due to the low concentration into organic solution. For the lowest concentration (near 1 $\mathrm{mg} . \mathrm{cm}^{-3}$ ) of $\beta$-carotene into organic solution, the $\mathrm{CO}_{2}$ may have acted as co-solvent. Thus, the encapsulated $\beta$-carotene determined at $\beta$-carotene concentration of $1 \mathrm{mg} . \mathrm{cm}^{-3}$ and PHBV concentration of $40 \mathrm{mg} . \mathrm{cm}^{-3}$ into organic solution and for the other conditions where the $\beta$-carotene concentration was approximately $1 \mathrm{mg} . \mathrm{mL}^{-1}$ can be due to the high pressure impregnation of $\beta$-carotene into polymer particles as the $\beta$-carotene dissolved in the organic solvent $+\mathrm{CO}_{2}$ mixture may be carried into the polymer particles remaining retained inside it.

The experimental run that presented the highest percentage of encapsulation was at $\beta$-carotene concentration into organic solution of $8 \mathrm{mg} . \mathrm{cm}^{-3}$ and PHBV concentration of 20 $\mathrm{mg} . \mathrm{cm}^{-3}$. Obviously, this is a condition for which the concentration of $\beta$-carotene into organic solution is close to saturation. In this case, according to the pure $\beta$-carotene precipitation, a high $\beta$-carotene concentration into organic solution leads to smaller precipitated particles compared to diluted $\beta$ carotene solutions. Thus, these fine particles can be easily covered by the polymer particles. In this experimental condi- 
Table 4. Results of the Percentage of Encapsulation and Encapsulation Efficiency for the Co-Preciptiation of $\beta$-Carotene and PHBV Using Dichloromethane as Organic Solvent and Supercritical Carbon Dioxide as Antisolvent

\begin{tabular}{|c|c|c|c|c|}
\hline Experimental Condition & $\begin{array}{c}\beta \text {-Carotene Concentration Into Organic } \\
\text { Solution }\left(\mathrm{mg} \cdot \mathrm{mL}^{-1}\right)\end{array}$ & $\begin{array}{l}\text { PHBV Concentration Into Organic } \\
\text { Solution }\left(\mathrm{mg} \cdot \mathrm{mL}^{-1}\right)\end{array}$ & $\begin{array}{l}\mathrm{PE} \\
(\%)\end{array}$ & $\begin{array}{l}\text { EE } \\
(\%)\end{array}$ \\
\hline 1 & 8.04 & 20.01 & 7.92 & 27.6 \\
\hline 2 & 6.01 & 19.99 & 6.69 & 29.0 \\
\hline 3 & 4.01 & 19.90 & 3.96 & 24.1 \\
\hline 4 & 2.02 & 20.04 & 1.99 & 22.0 \\
\hline 5 & 1.00 & 20.01 & 1.10 & 22.9 \\
\hline 6 & 8.07 & 30.08 & 3.59 & 17.1 \\
\hline 7 & 6.04 & 30.02 & 4.00 & 23.9 \\
\hline 8 & 4.04 & 30.07 & 4.10 & 34.7 \\
\hline 9 & 1.99 & 30.02 & 1.59 & 25.8 \\
\hline 10 & 0.99 & 30.00 & 0.87 & 28.1 \\
\hline 11 & 7.99 & 40.01 & 4.53 & 27.1 \\
\hline 12 & 6.03 & 40.03 & 3.10 & 23.8 \\
\hline 13 & 4.01 & 40.01 & 1.89 & 20.9 \\
\hline 14 & 2.01 & 40.09 & 1.24 & 25.0 \\
\hline 15 & 1.03 & 40.06 & 0.37 & 16.7 \\
\hline
\end{tabular}

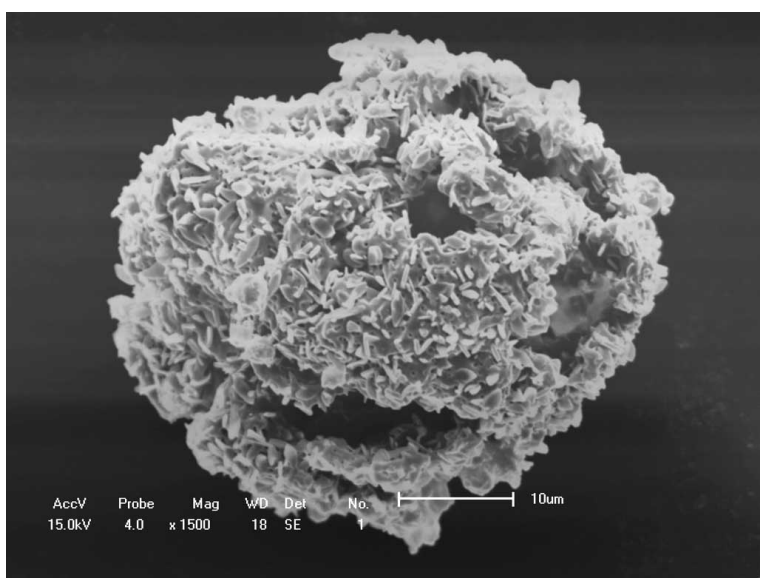

(A)

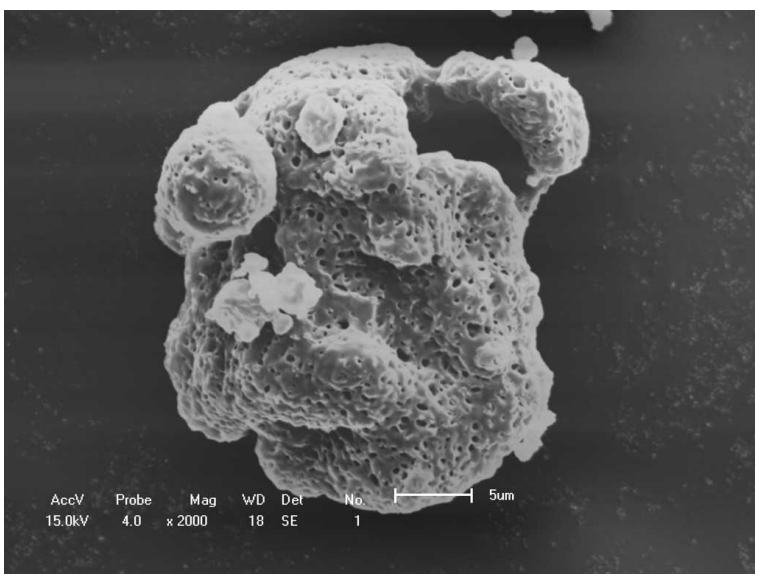

(B)

Fig. (4). SEM micrographs of co-precipitation condition with $\beta$-carotene and PHBV concentrations of $8 \mathrm{mg} . \mathrm{cm}^{-3}$ and $20 \mathrm{mg} . \mathrm{cm}^{-3}$, respectively, into organic solution. (A) magnification of 1500 times; (B) magnification of 2000 times. Precipitation pressure of 8.0 MPa, precipitation temperature of $313 \mathrm{~K}$, solution flow rate of $1 \mathrm{~cm}^{3} \cdot \mathrm{min}^{-1}$ and, antisolvent flow rate of $39 \mathrm{~g} \cdot \mathrm{min}^{-1}$.

tion (run 1) the encapsulation efficiency was not the highest probably due to the fact that most of the $\beta$-carotene particles generated was not totally covered by the polymer as can be seen in Fig. (4) that report SEM micrographs of experimental condition with $\beta$-carotene concentration into organic solution of $8 \mathrm{mg} \cdot \mathrm{cm}^{3}$ and PHBV concentration of $20 \mathrm{mg} \cdot \mathrm{cm}^{3}$.

As showed in Fig. (4A), part of $\beta$-carotene precipitated was attached onto the surface of the polymer particles and partially covered. In Fig. (4B) on the other hand there is not evidence of $\beta$-carotene particles on surface of polymer particles. However, the polymer particles seem to present a very high superficial porosity, indicating that part of $\beta$-carotene encapsulated might have been extracted during the removal step of non-encapsulated $\beta$-carotene.
The experimental condition with the best encapsulation efficiency was that where $\beta$-carotene and PHBV concentrations into organic solution were 4 and $30 \mathrm{mg} . \mathrm{cm}^{-3}$, respectively. These conditions allowed the simultaneous precipitation of $\beta$-carotene and PHBV and thus a more efficient encapsulation of $\beta$-carotene into PHBV particles (Fig. 5).

From Fig. (5A) it can be observe that the amount of $\beta$ carotene deposited on the surface of PHBV particle is smaller than that presented in Fig. (5B). In the last figure it is possible to observe that the particle surface is very smooth, with apparent no pores, meaning that in the removal process of non-encapsulated $\beta$-carotene, the encapsulated one was not extracted from the polymeric particles. 


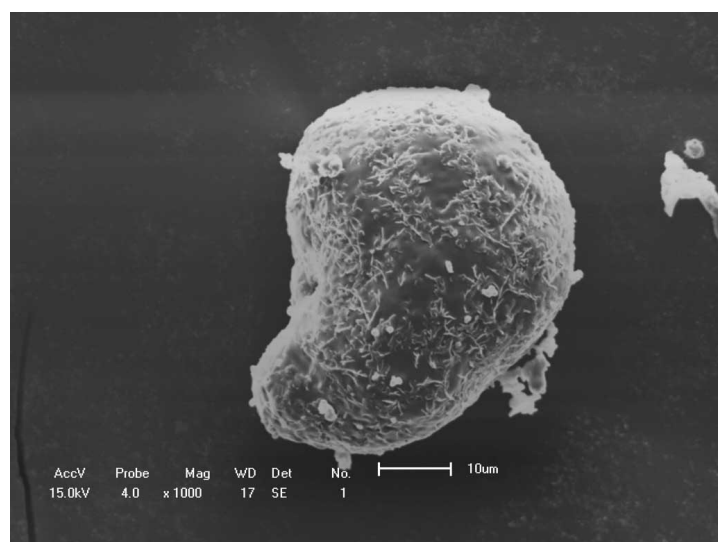

(A)

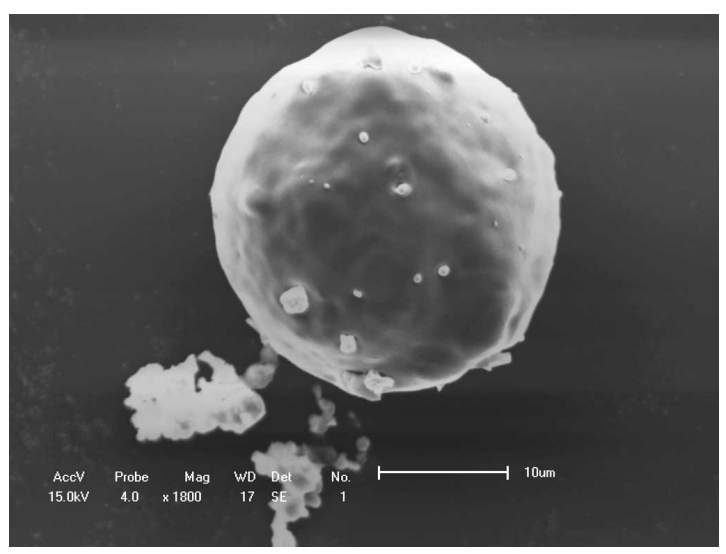

(B)

Fig. (5). SEM micrographs of experimental condition with $\beta$-carotene and PHBV concentrations of $4 \mathrm{mg} . \mathrm{cm}^{-3}$ and $30 \mathrm{mg} . \mathrm{cm}^{-3}$, respectively, into organic solution. Magnification of 1000 times (A) and 1800 times (B). Precipitation pressure of 8.0 MPa, precipitation temperature of $313 \mathrm{~K}$, solution flow rate of $1 \mathrm{~cm}^{3} \cdot \mathrm{min}^{-1}$ and, antisolvent flow rate of $39 \mathrm{~g} \cdot \mathrm{min}^{-1}$.

Some works presented in literature that report the encapsulation of carotenoids in biopolymers, relate the encapsulation efficiency with the modification of morphology of the pure polymer precipitated and the composite co-precipitated. When the morphology of the co-precipitated presents the same morphology of that of pure polymer particle, the authors suggest that an efficient encapsulation occurred [3, $12,32]$.

He et al. [17] carried out the co-precipitation of natural carotene and polyethylene glycol using dichloromethane as organic solvent and $\mathrm{CO}_{2}$ as antisolvent and reported percentage of encapsulation up to $50 \%$. However, in that work the authors did not remove the non-encapsulated carotene. They measure the percentage of encapsulation dissolving a sample of the co-precipitated in dichloromethane and analyzed by UV-visible spectrophotometry. Thus, it seems reasonable to believe that besides the carotene really encapsulated; also the attached carotene into polymer particle surface was considered.

Kalogiannis et al. [9] reported the percentage of encapsulation of amoxicillin in poly(lactic acid) in the range of 0.1 to $21.5 \%$ with encapsulation efficiency between 0.9 and $42.9 \%$. Kang et al. [29] in studying the encapsulation of indomethacin in a mixture of poly(lactic acid) and poly(lactyde-coglycolide) obtained a percentage of encapsulation up to $2.8 \%$ and encapsulation efficiency of $14 \%$. In these two last works the authors carried out a washing of the co-precipitated for the removal of the active compound non-encapsulated before the encapsulation percentage analysis. In the work of Kalogiannis et al. [9] the samples of co-precipitated were submitted to five washing steps whit ethanol and, in the work of Kang et al. [29] the samples of the co-precipitated were suspended in ethanol and agitated for 10 seconds, filtered and dried at controlled temperature for $24 \mathrm{~h}$ before the determining the percentage of encapsulation.

In this way, one may conclude that values obtained in this work regarding to percentage of encapsulation and mainly the encapsulation efficiency that is the amount of $\beta$ carotene present in the organic solution that was effectively encapsulated, are very suitable and are according to the expected results due to the methodology employed for the determination of the amount of $\beta$-carotene encapsulated into
PHBV particles, and also based on similar values reported in the literature for the encapsulation of other compounds $[9$, 29].

\section{CONCLUSIONS}

This work investigated the co-precipitation of $\beta$-carotene and PHBV from dichloromethane solutions by the SEDS technique with supercritical carbon dioxide as antisolvent. The methodology employed and the experimental procedure adopted for the co-precipitation showed to be easy, flexible and adequate to obtain microparticulate composites of $\beta$ carotene and PHBV. The conditions for the co-precipitation of $\beta$-carotene and PHBV were selected base on previous results from our working group. In this work, the parameters investigated were $\beta$-carotene concentration ( 1 to $8 \mathrm{mg} . \mathrm{cm}^{-3}$ ) and PHBV concentration (20 to $40 \mathrm{mg} . \mathrm{cm}^{-3}$ ) in the organic solution. The encapsulation results showed that the condition that presented the highest percentage of encapsulation (7.92 $\%)$ was that when using the most concentrated solution in $\beta$ carotene. The percentage of encapsulation obtained in this work agrees with literature values that reports similar results when employing the antisolvent technique with $\mathrm{CO}_{2}$. The methodology adopted for the quantification of $\beta$-carotene encapsulated was demonstrated to be adequate. The morphology of co-precipitated particles was spherical with very irregular and porous surface for some conditions and very smooth surfaces for others. These results show the viability of the processes that use supercritical fluids as antisolvents for the co-precipitation of active compounds and biopolymers for application in food products with the aim of extending the shelf life and to protect compounds from oxidation.

\section{ACKNOWLEDGEMENTS}

The authors thank CNPq and CAPES for the financial support and scholarships.

\section{RERECENCES}

[1] F. Miguel, A. Martín, T. Gamse, and M. J. Cocero, "Supercritical anti solvent precipitation of lycopene. Effect of the operating parameters", J. Supercrit. Fluids, vol. 36, pp. 225-235, 2006. 
[2] M. D. A. Saldaña, L. Sun, S. E. Guigard, and F. Temelli, "Comparison of the solubility of $\beta$-carotene in supercritical $\mathrm{CO}_{2}$ based on a binary and a multicomponent complex system", J. Supercrit. Fluids, vol. 37, pp. 342-349, 2006.

[3] A. Martín, F. Mattea, L. Gutiérrez, F. Miguel, and M. J. Cocero, "Co-precipitation of carotenoids and bio-polymers with the supercritical anti-solvent process", J. Supercrit. Fluids, vol. 41, pp. 138$147,2007$.

[4] A. Sánchez-Contreras, M. Jiménez, and S. Sánchez, "Bioconversion of lutein to products with aroma", Appl. Microbiol. Biotechnol., vol. 54, pp. 528-534, 2000 .

[5] W. A. Schroeder, and E. A. Johnston, "Singlet oxygen and peroxyl radicals regulate carotenoid biosynthesis in Phaffia rhodoxyma", $J$. Biol. Chem., vol. 270, pp. 18374-18379, 1995.

[6] S. Qing, K. G. Rowley, and N. D. H. Balazs, "CAROTENOIDS: Separation Methods Applicable to Biological Samples", J. Chromatogr. B, vol. 781, pp. 393-418, 2002.

[7] C. J. Chang, A. D. Randolph, N. E. Craft, "Separation of $\beta$ carotene mixtures precipitated from liquid solvents with highpressure $\mathrm{CO}_{2}$ ", Biotechnol. Prog., vol. 7, pp. 275-278, 1991.

[8] C. Vemavarapu, M. J. Mollan, M. Lodaya, and T. E. Needham, "Design and process aspects of laboratory scale SCF particle formation system", Int. J. Pharm., vol. 292, pp. 1-16, 2005.

[9] C. G. Kalogiannis, C. M. Michailof, and C. G. Panayiotou, "Microencapsulation of amoxicillin in poly(L-lactic acid) by supercritical antisolvent precipitation", Ind. Eng. Chem. Res., vol. 45, pp. 87388743, 2006.

[10] M. Bahrami, and S. Ranjbarian, "Production of micro- and nanocomposite particles by supercritical carbon dioxide", J. Supercrit. Fluids, vol. 40, pp. 263-283, 2007.

[11] S. -D. Yeo, and E. Kiran, "Formation of polymer particles with supercritical fluids: a review", J. Supercrit. Fluids, vol. 34, pp. 287-308, 2005.

[12] F. Mattea, M. Martin, and M. J. Cocero, "Co-precipitation of $\beta$ carotene and polyethylene glycol with compressed $\mathrm{CO}_{2}$ as an antisolvent: effect of temperature and concentration", Ind. Eng. Chem. Res., vol. 47, pp. 3900-3906, 2008.

[13] Y. Wang, Y. Wang, J. Yang, R. Pfeffer, R. Dave, and B. Michniak, "The application of a supercritical antisolvent process for sustained drug delivery", Powder Technol., vol. 164, pp. 94-102, 2006.

[14] N. Elvassore, A. Bertucco, and P. Caliceti, "Production of proteinloaded polymeric microcapsules by compressed $\mathrm{CO}_{2}$ in a mixed solvent", Ind. Eng. Chem. Res., vol. 40, pp. 795-800, 2001.

[15] I. Ribeiro dos Santos, J. Richard, B. Pech, C. Thies, and J. P. Benoit, "Microencapsulation of protein particles within lipids using a novel supercritical fluid process", Int. J. Pharm., vol. 242, pp. 6978, 2002.

[16] S. Salmaso, N. Elvassore, A. Bertucco, A. Lante, and P. Caliceti, "Nisin-loaded poly-L-lactide nano-particles produced by $\mathrm{CO}_{2}$ antisolvent precipitation for sustained antimicrobial activity", Int. J. Pharm., vol. 287, pp. 163-173, 2004.

[17] W. He, Q. Suo, H. Hong, A. Shan, C. Li, Y. Huang, Y. Li, and M. $\mathrm{Zhu}$, "Production of natural carotene-dispersed polymer microparticles by SEDS-PA co-precipitation", J. Mater. Sci., vol. 42, pp. 3495-3501, 2007.

[18] G. Q. Chen and Q. Wu, "The application of polyhydroxyalkanoates as tissue engineering materials", Biomaterials, vol. 26, pp. 6565$6578(2005)$
[19] M. S. Costa, A. R. C. Duarte, M. M. Cardoso, and C. M. M. Duarte, "Supercritical antisolvent precipitation of PHBV microparticles", Int. J. Pharm., vol. 328, pp. 72-77, 2007.

[20] E. Reverchon, I. De Marco, G. Caputo, and G. Della Porta, "Pilot scale micronization of amoxicillin by supercritical antisolvent precipitation", J. Supercrit. Fluids, vol. 26, pp. 1-7, 2003.

[21] M. Rantakylä, M. Jänti, O. Aaltonen, and M. Hurme, "The effect of initial drop size on particle size in the supercritical antisolvent precipitation (SAS) technique", J. Supercrit. Fluids, vol. 24, pp. 251263, 2002.

[22] E. Franceschi, M. H. Kunita, M. V. Tres, A. F. Rubira, E. C. Muniz, M. L. Corazza, C. Dariva, S. R. S Ferreira, and J. V. Oliveira, "Phase behavior and process parameters effects on the characteristics of precipitated theophylline using carbon dioxide as antisolvent", J. Supercrit. Fluids, vol. 44, pp. 8-20, 2008

[23] E. Franceschi, A. M. de Cesaro, M. Feiten, S. R. S. Ferreira, C. Dariva, M. H. Kunita, A. F. Rubira, E. C. Muniz, M. L. Corazza, and J. V. Oliveira, 2008a. "Precipitation of $\beta$-carotene and PHBV and co-precipitation from SEDS technique using supercritical $\mathrm{CO}_{2}{ }^{\prime}$, J. Supercrit. Fluids, vol. 47, pp. 259-269, 2008.

[24] E. Franceschi, A. M. de Cesaro, S. R. S. Ferreira, and J. Vladimir Oliveira, "Precipitation of b-carotene microparticles from SEDS technique using supercritical $\mathrm{CO}_{2}$ ", J. Food. Eng., vol. 95, pp. 656663, 2009.

[25] M. V. Tres, E. Franceschi, G. R. Borges, C. Dariva, F. C. Corazza, J. V. Oliveira, and M. L. Corazza, "Influência da temperatura na solubilidade de $\beta$-caroteno em solventes orgânicos a pressão ambiente", Ciênc. Tecnol. Aliment., vol. 27, pp.737-743, 2007.

[26] Y. Kang, G. Yin, P. Ouyang, Z. Huang, Y. Yao, X. Liao,A. Chen, and $\mathrm{X}$. Pu, "Preparation of PLLA/PLGA microparticles using solution enhanced dispersion by supercritical fluids (SEDS)", J. Coll. Int. Sci., vol. 322, pp. 87-94, 2008

[27] H. L. Hong, Q. L. Suo, W. Z. He, and C. P. Li, "Formation of carotene/proanthocyanidin composite microparticles via the solutionenhanced dispersion by supercritical fluids (SEDS) process through prefilming atomization", Ind. Eng. Chem. Res., vol. 46, pp. 66306634, 2007.

[28] V. Majerik, G. Charbit, E. Badens, G. Horváth, L. Szokonya, N Bosc, and E. Teillaud, "Bioavailability enhancement of an active substance by supercritical antisolvent precipitation", J. Supercrit. Fluids, vol. 40, pp. 101-110, 2007.

[29] Y. Kang, J. Wu, G. Yin, Z. Huang, Y. Yao, X. Liao, A. Chen, X. $\mathrm{Pu}$, and $\mathrm{L}$. Liao, "Preparation, characterization and in vitro cytotoxicity of indomethacin-loaded PLLA/PLGA microparticles using supercritical $\mathrm{CO}_{2}$ technique", Eur. J. Pharm. Biopharm., vol. 70, pp. 85-97, 2008 b.

[30] S. R. S. Ferreira, Z. L. Nikolov, L. K. Doraiswamy, M. A. A. Meireles, and A. J. Petenate, "Supercritical fluid extraction of black pepper (Piper nigrun L.) essential oil”, J. Supercrit. Fluids, vol. 14, pp. 235-245, 1999.

[31] S. R. S. Ferreira, and M. A. A. Meireles, "Modeling the supercritical fluid extraction of black pepper (Piper nigrun $L$.) essential oil", J. Food Eng., vol. 54, pp. 263-269, 2002.

[32] F. Miguel, A. Martín, F. Mattea, and M. J. Cocero, "Precipitation of lutein and co-precipitation of lutein and poly-lactic acid with the supercritical anti-solvent process", Chem. Eng. Proc., vol. 47, pp. 1594-1602, 2008.

(C) Franceschi et al.; Licensee Bentham Open .

This is an open access article licensed under the terms of the Creative Commons Attribution Non-Commercial License (http://creativecommons.org/licenses/by-nc/3.0/) which permits unrestricted, non-commercial use, distribution and reproduction in any medium, provided the work is properly cited. 